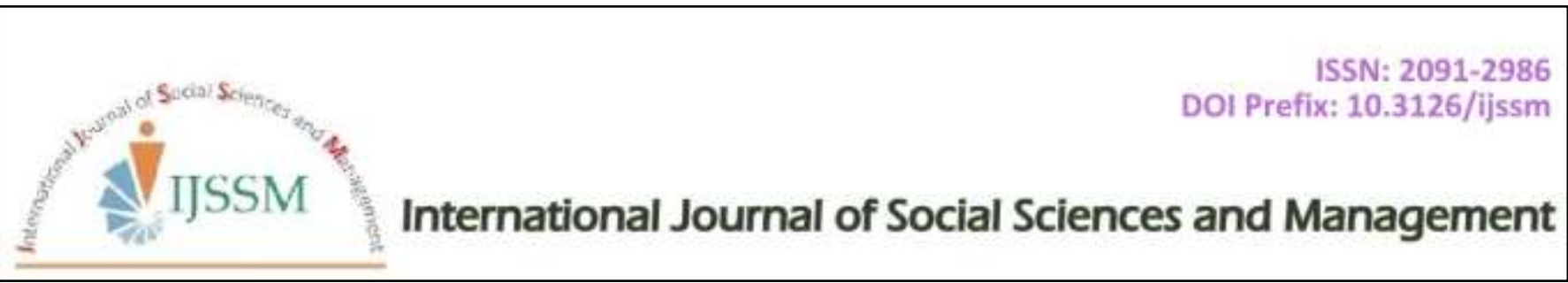

Research Article

\title{
Physical Violence Against Women During Pregnancy
}

\author{
Salwana Shamaun $^{1}$, Humaira Siddique ${ }^{2}$, Junaid Subhani ${ }^{3}$, Ali Waqas ${ }^{3 *}$, Kalsoom ${ }^{4}$ \\ ${ }^{1}$ Hameed Latif Hospital, Lahore, Pakistan \\ ${ }^{2}$ Services Hospital Lahore, Pakistan \\ ${ }^{3}$ Nursing College, The Superior College Lahore, Pakistan \\ ${ }^{4}$ Nursing College, Allama Iqbal Medical College, Pakistan
}

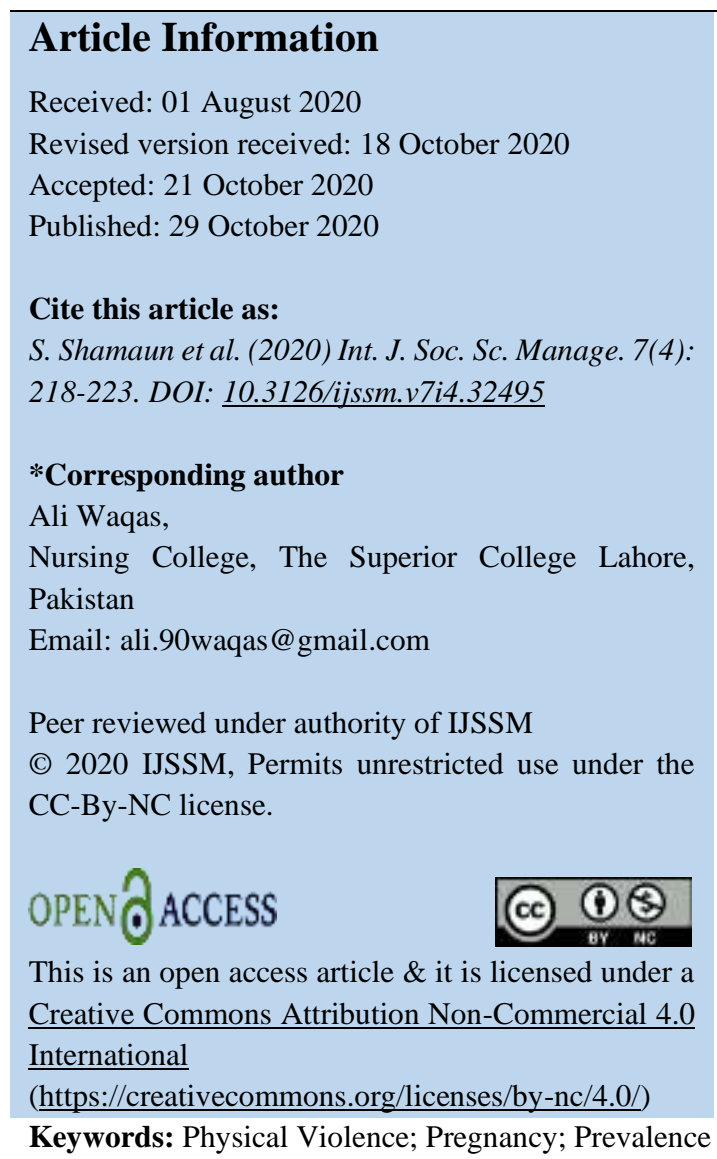

\begin{abstract}
The objective of this study was to determine the prevalence of physical violence during pregnancy and the factors associated with it. Although the whole world has recognized the violence against women is a serious risk to the health and development of the whole country. Butt still, it exists in almost all parts of the world. It is found more prevalent in developing countries as compared to the developed countries. This aspect signifies the socioeconomic aspect of the country. This study was performed by random sampling in gynae units of Jinnah hospital Lahore. Total 100 women were given the questionnaire and collected through the help of department's personnel. The results revealed the predominance of factors that cause and aggravate the violence against women during pregnancy.
\end{abstract}

\section{Introduction}

Domestic violence against women is reported among lower and middle class as well. However, many cases of severe violence are even not reported because of family pressure. The most significant of the domestic violence is physical violence during pregnancy. The consequences of this type of violence are very damaging and long-lasting. Violence

during pregnancy so badly effect not just mother's health both physically and mentally, but also damages the health and well-being of next generation. This situation of ignorance passes on generation to generation due to lack of awareness (Ellsberg et al., 2008). 
Physical violence during pregnancy is defined as "moderate to severe violence experience with one or more of the following behaviors: hit, beat or kick, slap, threatened by a weapon or in any other way during pregnancy" (Watts and Zimmerman, 2002). The risk factors behind occurrence of such events are low socioeconomic status, low level of social support, suspicion of infidelity or husband accusing wife of an affair, dowry harassment, low education of husband and husband being regularly drunk (Coker et al., 2004).

Secondly, great concern risk factors related to women experiencing physical violence during pregnancy include being single, being young, poor, deprived of antenatal care, unintentional pregnancy or being unhappy about having pregnancy (Peedicayil et al., 2004). The prevalence of physical violence during pregnancy is estimated based on reported cases. It ranges from $0.9 \%$ to $20 \%$. However, $04 \%$ of women experiencing violence during their lifetime have also experienced violence during pregnancy (Gazmararian et al., 1996). Violence against women by an intimate partner range from $9.7 \%$ to $30 \%$. Further, Illiteracy is the main factor behind violence by intimate partner (Marwick, 1998).

It is a known fact that our society is a male dominant society. In this context, power is assigned on gender basis and that power gives the right to men to physically beat their wives and daughters (Martin et al., 1999). The most miserable condition in most of cases is that, it is not taken as violence but as a cultural phenomenon. So, it's very difficult task to eradicate such events from society. However, awareness among both genders is the sole solution to that problem. Especially, awareness among women about their legal rights and health is of vital importance (McFarlane et al., 1992).

Even, if nobody is socially supporting the women, state and law is here to provide security to the women. As far as, the role of state and law is concerned, there is a significant difference among developed and developing countries (Glander et al., 1998). In developed countries, the strict situation of law and its implementation is the sign for control violence against women. While in developing countries, the prevalence of old beliefs and myths and cultural values are the main factors promoting violence during pregnancy. So, that difference is significant enough to undertake that problem and to take appropriate steps to eradicate that damaging problem (Audi et al., 2008). Likewise, women in Pakistan also experience the physical violence in home and during pregnancy as well which have effect on the baby and mother's metal health. Thus, this study assesses the prevalence of the physical violence among the women of public hospitals of Lahore, Pakistan.

\section{Literature Review}

Violence against women is widely recognized as a serious issue. Thus, consideration of violence against women issue for investigation is necessary. Death is the most severe consequence of violence against women (Bessa et al., 2014). As far as study and research about violence against women is concerned, WHO noted that $30 \%$ of women experienced violence by intimate partner and $7.2 \%$ of women reported non-partner sexual assault. This type of violence has worst effects on women physical and mental health. Social responses to this assault include restraining orders and mandatory arrest policies. WHO suggests the need for more effective interventions to reduce sexual violence against women (Peedicayil et al., 2004).

One of the sensitive forms of violence during pregnancy is physical violence. If we review literature about this vital issue, the prevalence was from $0.9 \%$ to $20.1 \%$. Violence against women during pregnancy is the condition which poses greater risks to the health of both mother and child due to violence (Olweus and Limber, 2017). Violence during pregnancy comes under the sky of domestic violence which refers to all forms of violence in the family environment (Iliyasu et al., 2013). However, the study mentions that prevalence of domestic violence against women varies from 10 to $70 \%$ (Santos et al., 2010).

World Health organization has emphasized on the various kind of violence i.e. violence by intimate partner is 15 to $71 \%$, physical violence is 4 to $54 \%$ and sexual violence is 4 to $50 \%$ (Arslantaş et al., 2012). However, prevalence of physical violence against women in various countries i.e. In Japan prevalence is $8 \%$, In Servia and Montenegro, it is $13 \%$. In Thailand this prevalence is $11 \%$, in Brazil, it is $32 \%$ and in the province of Peru, that is $44 \%$. After a huge study about violence, the major reason behind this violence comes to know is low socioeconomic level of women and their intimate partner (Arslantaş et al., 2012).

\section{Methodology}

This study is of descriptive and cross-sectional design which aims to analyze the prevalence of physical violence against women during pregnancy. The participants of this study were the patients from gynae unit I, II and III of Jinnah Hospital Lahore. Physical violence was measured through the questionnaire developed by Levy and Lemeshow (1965) based on the categorical scale (1: Yes \& 2: No). The self-administered questionnaire was distributed through simple random sampling technique to 100 pregnant women who were visiting Gynae ward of Jinnah Hospital Lahore for treatment. For data collection, the permission from the hospital administration was taken and consent of the respondents was also taken.

Data was analyzed using SPSS statistics 21. The participants general characteristics, physical violence during pregnancy were analyzed with descriptive statistics including frequency, percentage, mean, standard deviation etc. To determine the prevalence of physical violence the 
respondent's response was analyzed through frequency distribution.

\section{Results and Discussion}

\section{Age Group}

Table 1 shows that $34 \%$ of the pregnant women were among the age group of $18-25$ years, $36 \%$ of women were among the age group of 25-35 years, $22 \%$ women were among the age group of $35-50$ years and $8 \%$ of women were above the age of 50 years.

\section{Marital Status}

Table 2 shows the result that all women in the current study as participants were married.

\section{Qualification}

Table 3 shows that $52 \%$ of women have done matric, $17 \%$ of women have done intermediate and $31 \%$ women did graduation.

\section{Number of Children}

Table 4 shows that $19 \%$ of women had 1 child, $24 \%$ of women had 2 children, $19 \%$ of women had 3 children, $14 \%$ of women had 4 children and $24 \%$ had 5 children.

Table 1: Age of the respondents

\begin{tabular}{llrrrr}
\hline & & Age group & & \\
& & Frequency & Percent & Valid Percent & Cumulative Percent \\
\hline Valid & $18-25$ & 34 & 34.0 & 34.0 & 34.0 \\
& $25-35$ & 36 & 36.0 & 36.0 & 70.0 \\
& 22 & 22.0 & 22.0 & 92.0 \\
& & $85-50$ & 8.0 & 8.0 & 100.0 \\
above 50 & 100 & 100.0 & 100.0 & \\
\hline
\end{tabular}

Table 2: Marital status of the respondents

\section{Marital status}

\begin{tabular}{|c|c|c|c|c|c|}
\hline & & Frequency & Percent & Valid Percent & Cumulative Percent \\
\hline Valid & Married & 100 & 100.0 & 100.0 & 100.0 \\
\hline
\end{tabular}

Table 3: Qualification of the respondents

Qualification

\begin{tabular}{llllll}
\hline & Frequency & Percent & Valid Percent & Cumulative Percent \\
\hline Valid & matric & 52 & 52.0 & 52.0 & 52.0 \\
& intermediate & 17 & 17.0 & 17.0 & 69.0 \\
graduation & 31 & 31.0 & 31.0 & 100.0 \\
Total & 100 & 100.0 & 100.0 & \\
\hline
\end{tabular}

Table 4: Number of Children

\section{Number of children}

\begin{tabular}{llllll}
\hline & & Frequency & Percent & Valid Percent & Cumulative Percent \\
\hline Valid & 1 & 19 & 19.0 & 19.0 & 19.0 \\
& 2 & 24 & 24.0 & 24.0 & 43.0 \\
3 & 19 & 19.0 & 19.0 & 62.0 \\
4 & 14 & 14.0 & 14.0 & 76.0 \\
5 & 24 & 24.0 & 24.0 & 100.0 \\
\hline
\end{tabular}


Question \#1: Do you have experienced any type of violence during pregnancy?

Table 5 shows that $47 \%$ women experience any type of violence during pregnancy while $53 \%$ response negative to this question.

\section{Question \#2: Do you have experienced slap from your husband or anyone else during pregnancy?}

Table 6 shows that $48 \%$ of women experienced slap from their husband or anyone else during pregnancy and $52 \%$ of women gave response in negation to this question.
Question \#3: Do you are beaten by your family during pregnancy?

Table 7 shows that $25 \%$ of women were beaten by their family during pregnancy and $75 \%$ of women responded in negation to this statement.

Question \#4: Have anyone hit you during pregnancy?

Table 8 shows that $26 \%$ of women were hit during pregnancy by anyone in the in laws while $74 \%$ of women have not experienced that type of violence.

Question \#5: Do you are ever threatening with weapon during pregnancy?

Table 9 shows that only $7 \%$ of women were threatened with weapon during pregnancy while $93 \%$ of the women were disagreeing this.

Table 5: Do you have experienced any type of violence during pregnancy?

\begin{tabular}{llllll}
\hline & & Frequency & Percent & Valid Percent & Cumulative Percent \\
\hline Valid & yes & 47 & 47.0 & 47.0 & 47.0 \\
& no & 53 & 53.0 & 53.0 & 100.0 \\
& Total & 100 & 100.0 & 100.0 & \\
\hline
\end{tabular}

Table 6: Do you have experienced slap from your husband or anyone else during pregnancy?

\begin{tabular}{llllll}
\hline & & Frequency & Percent & Valid Percent & Cumulative Percent \\
\hline Valid & yes & 48 & 48.0 & 48.0 & 48.0 \\
& no & 52 & 52.0 & 52.0 & 100.0 \\
\hline
\end{tabular}

Table 7: Do you are beaten by your family during pregnancy?

\begin{tabular}{llllll}
\hline & & Frequency & Percent & Valid Percent & Cumulative Percent \\
\hline Valid & yes & 25 & 25.0 & 25.0 & 25.0 \\
& no & 75 & 75.0 & 75.0 & 100.0 \\
& Total & 100 & 100.0 & 100.0 & \\
\hline
\end{tabular}

Table 8: Have anyone hit you during pregnancy?

\begin{tabular}{llllll}
\hline & & Frequency & Percent & Valid Percent & Cumulative Percent \\
\hline Valid & yes & 26 & 26.0 & 26.0 & 26.0 \\
& no & 74 & 74.0 & 74.0 & 100.0 \\
& Total & 100 & 100.0 & 100.0 & \\
\hline
\end{tabular}

Table 9: Do you are ever threatening with weapon during pregnancy?

\begin{tabular}{llllll}
\hline & & Frequency & Percent & Valid Percent & Cumulative Percent \\
\hline Valid & yes & 7 & 7.0 & 7.0 & 7.0 \\
& no & 93 & 93.0 & 93.0 & 100.0 \\
& Total & 100 & 100.0 & 100.0 & \\
\hline
\end{tabular}




\section{Question \#6: Do your husband drunks?}

Table 10 shows that husbands of $19 \%$ of women were agree that their husbands used to drink while $81 \%$ of women responded in denial.

Question \#7: Do your husband has outside affairs?

Table 11 shows that $32 \%$ of women's husband had affairs outside while $68 \%$ of women said no to this statement.
Question \#8: Do your husband smoke or take drugs?

Table 12 describes that $45 \%$ of women said that their husbands used to smoke and take drugs while $55 \%$ of women said no to this statement.

\section{Question \#9: Do you have social support from your in- laws?}

Table 13 shows that $62 \%$ women have social support from their in-laws while $38 \%$ were abandoned of this support.

Question \#10: Is there any witness of your violence?

Table 14 shows that $34 \%$ women had witness of their violence while $66 \%$ women had not.

Table 10: Do your husband drunks?

\begin{tabular}{llllll}
\hline & & Frequency & Percent & Valid Percent & Cumulative Percent \\
\hline Valid & yes & 19 & 19.0 & 19.0 & 19.0 \\
& no & 81 & 81.0 & 81.0 & 100.0 \\
& Total & 100 & 100.0 & 100.0 & \\
\hline
\end{tabular}

Table 11: Do your husband has outside affairs?

\begin{tabular}{llllll}
\hline & Frequency & Percent & Valid Percent & Cumulative Percent \\
\hline Valid & yes & 32 & 32.0 & 32.0 & 32.0 \\
& no & 68 & 68.0 & 68.0 & 100.0 \\
& Total & 100 & 100.0 & 100.0 & \\
\hline
\end{tabular}

Table 12: Do your husband smoke or take drugs?

\begin{tabular}{|c|c|c|c|c|c|}
\hline 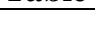 & & Frequency & Percent & Valid Percent & Cumulative Percent \\
\hline \multirow[t]{3}{*}{ Valid } & yes & 45 & 45.0 & 45.0 & 45.0 \\
\hline & No & 55 & 55.0 & 55.0 & 100.0 \\
\hline & Total & 100 & 100.0 & 100.0 & \\
\hline
\end{tabular}

Table 13: Do you have social support from your in-laws?

\begin{tabular}{llllll}
\hline & & Frequency & Percent & Valid Percent & Cumulative Percent \\
\hline Valid & yes & 62 & 62.0 & 62.0 & 62.0 \\
& No & 38 & 38.0 & 38.0 & 100.0 \\
& Total & 100 & 100.0 & 100.0 & \\
\hline
\end{tabular}

Table 14: Is there any witness of your violence?

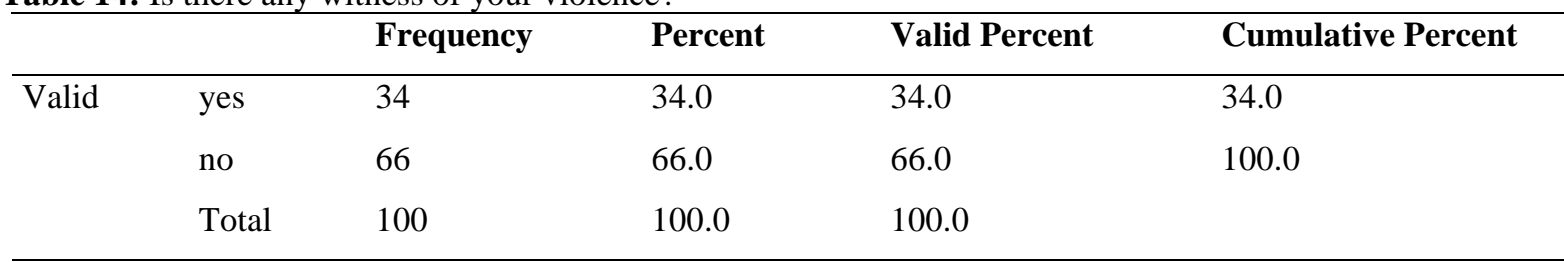


This study aims to assess the prevalence of violence against the pregnant woman. This study results show that violence against women is directly related to the low socio-economic level of the women and their intimate partner. Moreover, in Pakistan, there are other factors like joint family system, poverty, ignorance, less awareness among women about their rights and family pressures etc.

According to this study results, $47 \%$ of women reported violence during pregnancy. That is alarming situation about the condition of law and order. In this study, $48 \%$ of women reported that they bear the slap by their husband during the pregnancy, $25 \%$ women reported the episodes of beating by their family during the pregnancy, $26 \%$ women reported the history of hit outside the home during pregnancy, only $7 \%$ of women were threatened with weapon during pregnancy, $19 \%$ women's husband used to drink, $32 \%$ of women's husband has outside affairs that is strong reason for violence against women. $45 \%$ of women's husband used to smoke or take drugs, $62 \%$ of women have social support from their in-laws and $34 \%$ women reported that there are witness of violence against them. However, the issue of violence is more prevailed among the pregnant women of low socioeconomic backgrounds.

In Pakistan, majority of male prefer their ego. They think that they have right to abuse and beat the women. This is due to illiteracy and ignorance among lower class families.

\section{Conclusion}

The current study aims to assess the prevalence of violence against the pregnant women visiting the public hospitals for treatment. The results show that prevalence of physical violence against the pregnant women is higher among the visitors of public hospitals. However, major reason of violence against the working women is the low socioeconomic condition. Similarly, other factors behind this physical violence include inequalities reinforced by cultural, social and religious aspects.

\section{References}

Arslantaş H, Adana F, Ergin F, Gey N, Biçer N and Kıranşal N (2012) Domestic violence during pregnancy in an eastern city of Turkey: a field study. Journal of interpersonal violence 27(7): 1293-1313.

Audi CAF, Segall-Corrêa AM, Santiago SM, Andrade MdGG and Pèrez-Escamila R. (2008) Violence against pregnant women: prevalence and associated factors. Revista de saude publica 42(5): 877-885.
Bessa MMM, Drezett J, Rolim M and de Abreu LC (2014) Violence against women during pregnancy: sistematized revision. Reprodução \& Climatério 29(2): 71-79.

Coker AL, Sanderson M and Dong B (2004) Partner violence during pregnancy and risk of adverse pregnancy outcomes. Paediatric and perinatal epidemiology 18(4): 260-269.

Ellsberg M, Jansen HA, Heise L, Watts CH and Garcia-Moreno C (2008) Intimate partner violence and women's physical and mental health in the WHO multi-country study on women's health and domestic violence: an observational study. The Lancet 371(9619):1165-1172.

Gazmararian JA, Lazorick S, Spitz AM, Ballard TJ, Saltzman LE and Marks JS (1996) Prevalence of violence against pregnant women. JAMA 275(24): 1915-1920.

Glander S, Moore M, Michielutte R and Parsons L (1998) The prevalence of domestic violence among women seeking abortion. Obstetrics \& Gynecology 91(6): 1002-1006.

Iliyasu Z, Abubakar IS, Galadanci HS, Hayatu Z and Aliyu MH. (2013) Prevalence and risk factors for domestic violence among pregnant women in northern Nigeria. Journal of interpersonal violence 28(4): 868-883.

Martin SL, Tsui AO, Maitra K and Marinshaw R. (1999) Domestic violence in northern India. American journal of epidemiology 150(4): 417-426.

Marwick C (1998) Domestic violence recognized as world problem. JAMA 279(19): 1510-.

McFarlane J, Parker B, Soeken K and Bullock L (1992) Assessing for abuse during pregnancy: severity and frequency of injuries and associated entry into prenatal care. JAMA 267(23): 3176-3178.

Olweus D, Limber SP (2017) Some Problems with Cyberbullying Research. Current Opinion in Psychology.

Peedicayil A, Sadowski LS, Jeyaseelan L, Shankar V, Jain D, Suresh S, et al. (2004) Spousal physical violence against women during pregnancy. BJOG: An International Journal of Obstetrics \& Gynaecology 111(7): 682-687.

Santos SA, Lovisi GM, Valente CdCB, Legay L and Abelha L (2010) Violência doméstica durante a gestação: um estudo descritivo em uma unidade básica de saúde no Rio de Janeiro. Cad Saúde Colet 18(4): 483-493.

Watts C and Zimmerman C (2002) Violence against women: global scope and magnitude. The lancet. 359(9313): 12321237. 